\title{
Coercion and admission in psychiatric facilities
}

Psychiatric care in India has always taken a back seat when compared to Western nations. The stigma and the shame associated with mental illness in the Indian subcontinent are often a cause for psychiatric patient delaying treatment. This is also one of the reasons as to why most patients and their family members refuse inpatient treatment. Treatment facilities for psychiatric disorders in India range between few private psychiatric hospitals and rehabilitation centers, which may or may not be affordable to all, and general hospital psychiatric units (GHPUs) ${ }^{[1]}$ The GHPU is often attached to a medical college or a tertiary general hospital. It is worthwhile mentioning that majority of psychiatric admissions happen here. The GHPU was not in the purview of the Mental Health Act, 1987, but may be brought under the purview of the Mental Health Care Bill, 2013. GHPUs are the backbone of psychiatric infrastructure run by the government and play a major role in reducing stigma being attached to a general hospital. The wards in a GHPU are not locked, and usually, a relative has to stay with the patient that may often be supportive and conducive to his recovery. Government mental hospitals are often equated with mental asylums of the bygone era by the common man and admission to such a hospital is often viewed with shame, stigma, and disdain. ${ }^{[2]}$

It is important to understand that most psychiatric patients who require inpatient management may have no insight into their conditions, may refuse to take treatments, and also show decreased self-care, reduced food intake, and suicidal behavior. A patient who has insight and understands that he is psychiatrically ill may rarely need inpatient treatment except when emergencies arise. The most common psychiatric disorders seen in clinical practice are depression, anxiety disorders, and schizophrenia. ${ }^{[3]}$ Patients with schizophrenia often have no insight into their problems and form the major group of inpatients in any psychiatric facility. ${ }^{[4]}$ While we may propose that involuntary admissions are unjust and unfair, it is essential to understand that when a patient has no insight and is unmanageable, this may be the only resort left before his caregivers. The involuntary admission carried out through force or coercion by his relatives is often for his own betterment and treatment rather than to violate his human rights. Mental health professionals must be aware of the fact that psychiatric patients can be manipulated and taken advantage of. Every case must be evaluated thoroughly from a family and psychosocial dimension before suggesting inpatient care so that relatives with vested interests and vying for the patient's property or finances do not get a chance to prove him mentally ill or unstable. Coercive psychiatric admissions are often regarded as a violation of the human rights of the psychiatrically ill. ${ }^{[5]}$ India has been witness to many human rights tragedies concerning the mentally ill like the recent Erwadi event. ${ }^{[6]}$ While the rights and dignity of any human being including the psychiatrically ill are paramount, the context of events concerned must be given consideration.

The Mental Health Care Bill, 2013, speaks of having the patient decide what form of treatments he or she would wish to undergo and whether or not they would prefer inpatient treatment. This may be feasible if the patient has good insight but may not be possible in cases with poor insight. The patient even with poor insight shall have the right to request review by the Mental Health Review Board to decide whether he needs inpatient treatment. It is important that members of this board are trained adeptly in identifying and diagnosing psychiatric disorders while they take this decision. Many patients with schizophrenia or bipolar disorder often speak normally when put before a doctor or the court of law and it is close relatives who bear the brunt of their paranoia, mania, delusions, and violent behavior that ensues. Doctors who may admit a patient to treat him may sometimes have to release such a patient if the review board advises so. This may not do well for the patient who may continue to remain untreated for longer periods of time. There would also have to be an adequate number of review boards to cater to the needs of various psychiatric facilities and the quantum of inpatient admissions that may happen. An interesting scenario may be substance abuse and alcohol use disorders where the patient continues to use substances and alcohol despite knowing that it is harmful to him and has fair insight into his condition. Such a patient may lie, steal, and get aggressive at home and with others while refusing treatment if given a chance to decide what is best for him. The Mental Health Review Board shall need to be trained with such eventualities and must be equipped to deal with them. There are many facets of psychiatric 
admission and management that need to be clarified under the new bill to handle such circumstances. ${ }^{[7]}$

When one speaks of coercion in psychiatric treatment, it is also important to look at the perspective in which it happens. Coercion to violate the human rights of someone psychiatrically ill is unacceptable. The same coercion when imposed by relatives to help them recover, take treatment, and achieve a better quality of life in the long run may not be in their negative interest. A father forcing his son suffering from paranoid schizophrenia to seek treatment must be viewed as a cry for help for his kin rather than coercion while a relative forcing a patient to get admitted to usurp his wealth and property is definitely coercion with all the wrong intentions. An article published in the current issue of the journal speaks of coercion with respect to admission to psychiatric facilities and says that though coercion perceived may have been low, an element of threat was perceived.$^{[8]}$ This can be due to the fact that psychiatric inpatient setups are often imposing and admission to a mental health facility is itself stigmatizing. Apart from this, the patient who has delusions and hallucinations may find his world breaking, a world in which he was very comfortable for a few months and the belief that people are against him and want to harm gets reinforced when he is probably admitted against his will. The new Mental Health Care Bill, 2013, is a huge stride in the right direction but there are cracks in its armor that will widen once a day to day implementation of the act happens. Modifications of certain aspects of the act may be required when this arises. Till then, a judicious approach to inpatient psychiatric admissions is warranted.

\section{Avinash De Sousa}

Department of Psychiatry, Lokmanya Tilak Municipal Medical College, Mumbai, Maharashtra, India
Address for correspondence:

Dr. Avinash De Sousa,

Carmel, 18, St. Francis Road, Off. S. V. Road, Santacruz West,

Mumbai 400054, Maharashtra, India.

E-mail: avinashdes888@gmail.com

\section{References}

1. Khandelwal SK, Jhingan HP, Ramesh S, Gupta RK, Srivastava VK. India mental health country profile. Int Rev Psychiatry 2004;16:126-41.

2. Thara R, Srinivasan TN. How stigmatising is schizophrenia in India? Int J Soc Psychiatry 2000;46:135-41.

3. Math SB, Chandrashekar CR, Bhugra D. Psychiatric epidemiology in India. Indian J Med Res 2007;126:183-92.

4. Sharma S. Human rights of mental patients in India: A global perspective. Curr Opin Psychiatry 2003;16:547-51.

5. Drew N, Funk M, Tang S, Lamichhane J, Chávez E, Katontoka S, et al. Human rights violations of people with mental and psychosocial disabilities: An unresolved global crisis. Lancet 2011;378:1664-75.

6. Murthy SR. Lessons from the erwadi tragedy for mental health care in India. Indian J Psychiatry 2001;43:362-6.

7. Kala A. Time to face new realities; mental health care bill-2013. Indian J Psychiatry 2013;55:216-9.

8. Ramachandra, Poreddi V, Ramu R, Selvi S, Gandhi S, Krishnaswamy L, et al. Admission experiences of psychiatric patients in tertiary care: An implication towards mental health care bill; 2013. J Neurosci Rural Pract 2017;8:89-95.

This is an open access article distributed under the terms of the Creative Commons Attribution-NonCommercial-ShareAlike 3.0 License, which allows others to remix, tweak, and build upon the work non-commercially, as long as the author is credited and the new creations are licensed under the identical terms.

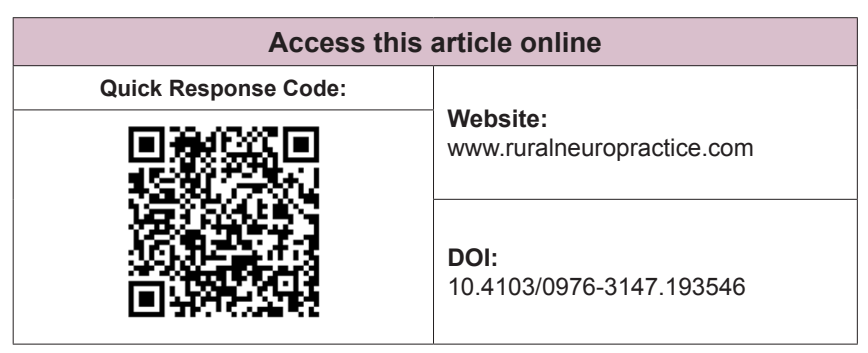

How to cite this article: De Sousa A. Coercion and admission in psychiatric facilities. J Neurosci Rural Pract 2017;8:1-2. 